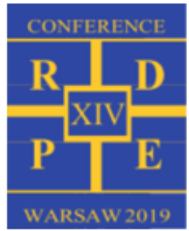

\title{
Transient behavior of a plate-fin-and-tube heat exchanger taking into account different heat transfer coefficients on the individual tube rows
}

\author{
Dawid Taler $^{1}$, Jan Taler ${ }^{2 *}$, and Katarzyna W rona ${ }^{3}$ \\ 1 Faculty of Environmental and Energy Engineering, Cracow University of Technology, ul. Warszawska 24, 31-155 Cracow, \\ dtaler@pk.edu.pl, Poland \\ 2* Faculty of Environmental and Energy Engineering, Cracow University of Technology, Al. Jana Pawła II 37, 31-864 Cracow, \\ jtaler@mech.pk.edu.pl, Poland \\ 3 Faculty of Environmental and Energy Engineering, Cracow University of Technology, Al. Jana Pawła II 37, 31-864 Cracow, \\ katarzynawrona@interia.com, Poland
}

\begin{abstract}
Plate-fin and tube heat exchangers (PFTHE) are made of round, elliptical, oval or flat tubes to which continuous fins ( lamellas) are attached. Liquid flows inside the tubes and gas flows outside the tubes perpendicularly to their axes and parallel to the surface of continuous fins. Experimental studies of multi-row plate-fin and tube heat exchangers show that the highest average heat transfer coefficient on the air side occurs in the first row of tubes when the air velocity in front of the exchanger is less than approximately $3.5 \mathrm{~m} / \mathrm{s}$ when a Reynolds number based on an equivalent hydraulic diameter equal to the distance between tube rows in the direction of air flow is less than 10,000 . In the subsequent rows of tubes up to about the fourth row the heat transfer coefficient decreases. In the fifth and further rows, it can, that the heat transfer coefficient is equal in each tube row. It is necessary to find the relationships for the air-side N usselt number on each tube row to design a PFTHE with the appropriate number of tube rows. The air-side N usselt number correlations can be determined experimentally or by CFD modeling (Computational and Fluid Dynamics). The paper presents a new mathematical model of the transient operation of PFTHE, considering that the N usselt numbers on the air side of individual tube rows are different. The heat transfer coefficient on an analyzed tube row was determined from the equality condition of mass- average air temperature differences on a given tube row determined using the analytical formula and CFD modeling. The results of numerical modeling were compared with the results of the experiments.
\end{abstract}

\section{Introduction}

Plate-fin and tube heat exchangers (PFTHEs) are widely used in air conditioning, heating, and many industries [1-4]. Inside the tubes, a liquid usually flows, e.g., water, glycol solution, or oil, and outside perpendicular to the tube axis air or exhaust gas or another gas. PFTHEs are very widely used in practice. For this reason, the number of books and articles in journals concerning their design, mathematical modeling, and experimental studies is very large. So far, both in the calculation of heat exchangers and in experimental studies, it has been assumed that the heat transfer coefficient (correlation for Nusselt number) on the gas side of each row of tubes is the same [1-4]. The fundamental experimental study showing the influence of the number of rows of tubes on the Colburn parameter for the entire exchanger as well as for the individual rows of tubes was performed by Rich [5]. The research carried out by Saboya and Sparrow [6] using the technique of naphthalene sublimation of for one-, two- and three-row system with staggered tube configurations confirmed Rich $\odot$ observations. If the number of tube rows is less than four, the correlation for the Nusselt number on the gas side is usually determined separately for a one-, two-, three- or four-row exchanger. If the number of tube rows in the heat exchanger is greater than four, it is assumed that the addition of the fifth and further tube rows does not affect the average heat transfer coefficient of the whole heat exchanger [2-3,7]. U sually, the correlation $j_{N=4}$ for the Colburn factor for a four-row heat exchanger is given, assuming that it is also valid for heat exchangers with more rows of tubes. The $j_{N} / j_{N=4}$ correction for a heat exchanger with a smaller number of tube rows, i.e., a single, double or triple row heat exchanger, is a function of the number of tube rows and the Reynolds number. Correlations for the calculation of Colburn @ factors $j_{N=4}$ and $j_{N}$ were proposed for staggered tube alignment by M cQuiston [2-3] and Gray and W ebb [3] based, in part, on Rich $\odot$ experimental results [5].

The literature review shows that for air velocities before a PFTHE lower than $3.5 \mathrm{~m} / \mathrm{s}$, the first four rows of tubes exchange higher heat flow rates compared to the subsequent rows. The empirical heat transfer correlations available in the literature permit the calculation of average heat transfer coefficients for the entire heat exchanger with different tube rows. However, there are no 
correlations for the cal culation of the local air side N usselt numbers for the individual tube rows, especially for the first six rows. The air-side heat transfer correlations can be developed based on CFD modeling [8-12]. This paper proposes a calculation method of PFTHEs based on the air-side heat transfer correlations, obtained using CFD simulations [12]. The method of determining CFD based correlations should be compatible with the procedure of determining empirical heat transfer correlations, to ensure that the results of PFTHEs cal culations are consistent with the results of measurements. Semi-empirical relationships developed by Taler [13-16] were used to cal culate the heat transfer coefficients on the internal surfaces of tubes in the transition and turbulent flow regime. The formulas proposed by Gnielinski [17] were used to calculate the heat transfer coefficient in the laminar flow regime. By using reliable CFD correlations to calculate air-side heat transfer coefficients and semi-empirical relationships to calculate heat transfer coefficients on the internal surfaces of tubes, the experimental studies required can be significantly reduced, especially for PFTHEs with new design, e.g. made of tubes with different cross-section shapes or with different designs of continuous fins on the air-side. The PFTHEs numerical models can al so take into account different heat transfer coefficients on the air side of each tube row. The method of modeling PFTHEs in steady-state and transient states proposed in the paper together with the method of determining the air-side heat transfer correlations proposed in [12] will significantly reduce the cost and shorten the time of implementation of PFTHEs with new construction and flow system.

\section{Mathematical formulation}

The basis for the development of the mathematical model of the PFTHE is the set of energy conservation equations for water flowing through tubes, tube walls with fins, and for air flowing perpendicularly to the tube axes (Fig. 1) [18-19]. Due to the low thermal capacity of the air, the time derivative from the air temperature was omitted, i.e., the temperature distribution in the direction of its flow (in the $y$-axis direction) was determined from the solution of the steady-state energy conservation equation. The set of partial differential equations describing the space and time variations of water $T_{w}$, tube wall $T_{t}$, and air $T_{a}$ temperatures are

$$
\begin{gathered}
\frac{1}{N T U_{w}} \frac{\partial T_{w}}{\partial x^{+}}+\tau_{w} \frac{\partial T_{w}}{\partial t}=-\left(T_{w}-T_{t}\right) \\
\tau_{t} \frac{\partial T_{t}}{\partial t}+\tau_{f} \frac{\partial \bar{T}_{a}}{\partial t}+T_{t}=\frac{h_{w} U_{\text {in }}}{h_{w} U_{\text {in }}+h_{o} U_{\text {out }}} T_{w}+ \\
\frac{h_{o} U_{\text {out }}}{h_{w} U_{\text {in }}+h_{o} U_{\text {out }}} \bar{T}_{a} \\
\frac{1}{N T U_{a}} \frac{\partial T_{a}}{\partial y^{+}}=T_{t}-T_{a}
\end{gathered}
$$

where $\bar{T}_{a}$ denotes the mean air temperature over the row thickness, defined as

$$
\bar{T}_{a}=\int_{0}^{1} T_{a}\left(x^{+}, y^{+}, t\right) \mathrm{d} y^{+} .
$$

The numbers of heat transfer units $N T U_{w}$ and $N T U_{a}$ are defined as follows

$$
N T U_{w}=\frac{h_{w} A_{\text {in }}}{\dot{m}_{w} \bar{c}_{w}} \quad N T U_{a}=\frac{h_{o} A_{\text {out }}}{\dot{m}_{a} \bar{c}_{p a}}
$$

The time constants $\tau_{w}, \tau_{t}$, and $\tau_{f}$ are

$$
\begin{gathered}
\tau_{w}=\frac{m_{w} c_{p w}}{h_{w} A_{\text {in }}}, \quad \tau_{t}=\frac{\left(m_{t}+\eta_{f} m_{f}\right) c_{t}}{h_{w} A_{\text {in }}+h_{o} A_{\text {out }}}, \\
\tau_{f}=\frac{\left(1-\eta_{f}\right) m_{f} c_{t}}{h_{w} A_{\text {in }}+h_{o} A_{\text {out }}}, A_{\text {in }}=N_{t} P_{\text {in }} L_{t}, A_{\text {out }}=N_{t} P_{\text {out }} L_{t}, \\
A_{t}=\pi a b, \quad A_{\text {oval }}=\pi\left(a+\delta_{t}\right)\left(b+\delta_{t}\right), \quad \text { (6) } \\
m_{f}=N_{t} N_{f}\left(p_{1} p_{2}-A_{\text {oval }}\right) \delta_{f} \rho_{f}, \quad m_{t}=N_{t} P_{m} \delta_{t} L_{t} \rho_{t}, \\
m_{w}=N_{t} A_{t} L_{t} \rho_{w}, \quad P_{m}=\left(P_{\text {in }}+P_{\text {out }}\right) / 2
\end{gathered}
$$

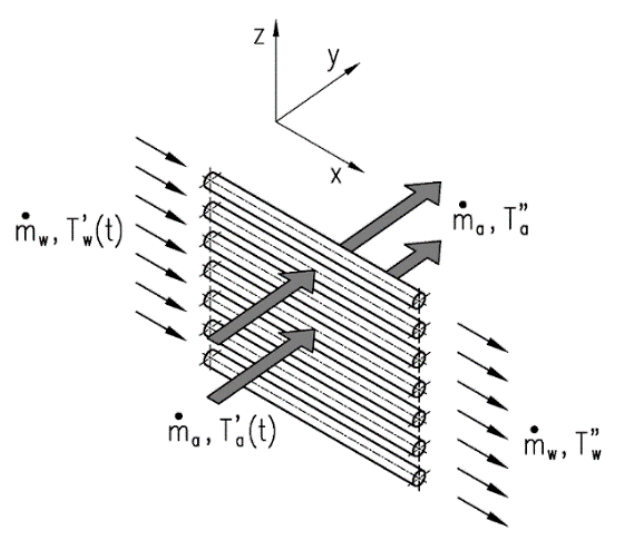

Fig. 1. Cross-flow tube heat exchanger with one row of tubes

The effective weighted heat transfer coefficient $h_{o}$ is given by

$$
h_{o}=h_{a}\left[\frac{A_{b f}}{A_{\text {out }}}+\frac{A_{f}}{A_{\text {out }}} \eta_{f}\left(h_{a}\right)\right]
$$

where: $a, b$ - minimum and maximum inner radius of the oval tube; $A_{f}$ - fin surface area; $A_{b f}$ - area of the tube outer surface between fins; $A_{\text {oval }}, A_{t}$ - outside and inside crosssection area of the oval tube; $A_{i n}=N_{t} P_{i n} L_{t}$, $A_{\text {out }}=N_{t} P_{\text {out }} L_{t}$ - inside and outside surface area of the bare tube; $c_{p}$ - specific heat at constant pressure; $c_{t}, c_{f}$ specific heat of the tube and fin material; $h_{w}$ and $h_{a}$ water and air side heat transfer coefficients, respectively; $h_{o}$-effective weighted heat transfer coefficient from the air side related to outer surface area of the bare tube; $L_{t}$ tube length in the heat exchanger; $m_{w}, m_{f}$, and $m_{t}$ - mass of the water, fins, and tube walls in the heat exchanger, $\dot{m}_{w}$ - mass flow rate of liquid flowing inside the tubes; $\dot{m}_{a}$ - air mass flow rate; $N_{f}$ - number of fins on the tube length; $N_{t}$ - number of tubes in the heat exchanger; $N T U_{w}$ and $N T U_{a}$ - number of heat transfer 
units for water and air, respectively; $p_{1}$ - pitch of tubes in plane perpendicular to flow (height of fin); $p_{2}$ - pitch of tubes in direction of flow (fin width); $s$ - fin pitch; $t$ time; $T_{w}, T_{t}$, and $T_{a}$ - water, tube wall and air temperature; $\bar{T}_{a}$ - mean air temperature on the thickness of one tube row; $P_{\text {in }}$ and $P_{\text {out }}$ - inner and outer tube perimeter of the bare tube, $\eta_{f}$ - fin efficiency; $x^{+}=x / L_{t}$ , $y^{+}=y / p_{2}$ - dimensionless Cartesian coordinates; $\delta_{f}$ and $\delta_{t}$ - fin and tube thickness, respectively; $\rho$ - density; $\tau_{w}, \tau_{t}$, and $\tau_{f}$ - time constant of water, tube, and fin, respectively.

The initial temperature distribution of the water $T_{\mathrm{w}, 0}\left(x^{+}\right)$, air $T_{a, 0}\left(x^{+}, y^{+}\right)$, and the tube walls $T_{t, 0}\left(x^{+}\right)$are known from measurements or the steady-state calculations of the PFTHE. The initial conditions are

$$
\begin{gathered}
\left.T_{w}\left(x^{+}, t\right)\right|_{t=0}=T_{w, 0}\left(x^{+}\right) \\
\left.T_{t}\left(x^{+}, t\right)\right|_{t=0}=T_{t, 0}\left(x^{+}\right) \\
\left.T_{a}\left(x^{+}, y^{+}, t\right)\right|_{t=0}=T_{a, 0}\left(x^{+}, y^{+}\right)
\end{gathered}
$$

The equation system (1)-(3) is subject to the following boundary conditions

$$
\begin{aligned}
& \left.T_{w}\left(x^{+}, t\right)\right|_{x^{+}=0}=T_{w}^{\prime}(t) \\
& \left.T_{a}\left(x^{+}, y^{+}, t\right)\right|_{y^{+}=0}=T_{a}^{\prime}(t)
\end{aligned}
$$

where $T_{w}^{\prime}(t)$ and $T_{a}^{\prime}(t)$ are functions representing the variations of the inlet temperatures of water and air in time. The initial-boundary problem formulated by Eqs (1-12) applies to the heat exchangers made of smooth tubes as well as to PFTHEs. The transient water, air, and wall temperature distributions in the one-row heat exchanger (Fig. 1) are then determined using the explicit finite difference method.

\section{Finite difference method of the PFTHE}

The temperature distribution $T_{w}\left(x^{+}, t\right), T_{t}\left(x^{+}, t\right)$ and $T_{a}\left(x^{+}, y^{+}, t\right)$ were determined by the explicit finite difference method. The time derivatives in Eqs (1)-(2) were approximated by forward differences, while the spatial derivatives were approximated by backward differences. Figure 2 shows a single difference cell.

The nodes where the water temperature is calculated are at the beginning and end of the cell, and the nodes where the air and tube wall temperatures are calculated at the middle of the cell@ length. The finite-difference grid is defined as follows

$$
x_{i}=(i-1) \Delta x, \quad i=1, \ldots, N+1, \quad t_{n}=n \Delta t,
$$$$
n=0,1, \ldots
$$

Eq. (3) was solved analytically, assuming that the tube wall temperature is constant within a single cell and equals

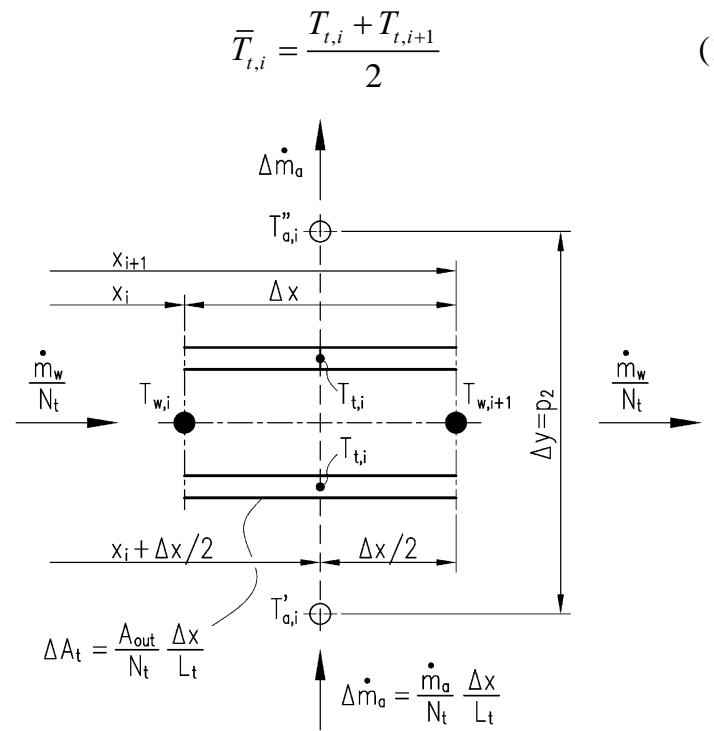

Fig. 2. A single cell (finite volume) in a finite difference grid

The solution of Eq.(3) for the boundary condition $\left.T_{a, i}\right|_{y^{+}=0}=T_{a, i}^{\prime}$ (Fig. 2) has the following form

$$
\begin{aligned}
& T_{a, i}=\bar{T}_{t, i}-\left(\bar{T}_{t, i}-T_{a, i}^{\prime}\right) \exp \left(-\frac{U_{o} \Delta A_{t}}{\Delta \dot{m}_{a} c_{p a}} y^{+}\right)= \\
& \bar{T}_{t, i}-\left(\bar{T}_{t, i}-T_{a, i}^{\prime}\right) \exp \left(-N T U_{a} y^{+}\right), \\
& \quad x_{i}^{+} \leq x^{+} \leq x_{i+1}^{+}, \quad i=1, \ldots, N, \quad 0 \leq y^{+} \leq 1
\end{aligned}
$$

where: $\Delta A_{t}=\frac{A_{\text {out }}}{N_{t}} \frac{1}{N}=P_{\text {out }} \Delta x$ and $\Delta \dot{m}_{a}=\frac{\dot{m}_{a}}{N_{t}} \frac{1}{N}$.

Substituting $y^{+}=1$ into Eq. (15) yields the air temperature $T_{a, i}^{\prime \prime}$ after the tube row

$$
\begin{gathered}
T_{a, i}^{\prime \prime}=\bar{T}_{t, i}-\left(\bar{T}_{t, i}-T_{a, i}^{\prime}\right) \exp \left(-N T U_{a}\right), \\
x_{i}^{+} \leq x^{+} \leq x_{i+1}^{+}, i=1, \ldots, N
\end{gathered}
$$

The integral mean temperature of the air over the thickness $\Delta y^{+}=1$ of one tube row can be determined using the definition (4)

$$
\begin{aligned}
& \bar{T}_{a, i}=\int_{0}^{1} T_{a, i}\left(y^{+}, t\right) d y^{+}=\bar{T}_{t, i}- \\
& \frac{1}{N T U_{a}}\left(\bar{T}_{t, i}-T_{a, i}^{\prime}\right)\left[\exp \left(-N T U_{a}\right)-1\right]
\end{aligned}
$$

Solving of finite difference equations for $T_{w, i+1}^{n+1}$ and $T_{t, i}^{n+1}$ gives

$$
\begin{aligned}
& T_{w, i+1}^{n+1}=T_{w, i+1}^{n}-\frac{\Delta t}{N T U_{w}^{n} \tau_{w}^{n}} \frac{T_{w, i+1}^{n}-T_{w, i}^{n}}{\Delta x^{+}}- \\
& \frac{\Delta t}{\tau_{w}^{n}}\left(\frac{T_{w, i}^{n}+T_{w, i+1}^{n}}{2}-T_{t, i}^{n}\right), \quad i=1, \ldots, N, \quad n=0,1, \ldots
\end{aligned}
$$




$$
\begin{aligned}
& T_{t, i}^{n+1}=T_{t, i}^{n}+\frac{\Delta t}{\tau_{t}^{n}}\left\{\frac{h_{w}^{n} A_{\text {in }}}{h_{w}^{n} A_{\text {in }}+h_{o}^{n} A_{\text {out }}} \frac{T_{w, i}^{n}+T_{w, i+1}^{n}}{2}+\right. \\
& \left.\frac{h_{o}^{n} A_{\text {out }}}{h_{w}^{n} A_{\text {in }}+h_{o}^{n} A_{\text {out }}} \bar{T}_{a, i}^{n}-T_{t, i}^{n}-\frac{\tau_{f}^{n}}{\Delta t}\left[\bar{T}_{a, i}^{n+1}-\bar{T}_{a, i}^{n}\right]\right\}, \\
& i=1, \ldots, N, \quad n=0,1, \ldots
\end{aligned}
$$

The average air temperature over the thickness of one tube row occurring in equation (19) is given by the following expression

$$
\begin{aligned}
& \bar{T}_{a, i}^{n}=\bar{T}_{t, i}^{n}-\frac{1}{N T U_{a}^{n}}\left[\bar{T}_{t, i}^{n}-\left(T_{a, i}^{\prime}\right)^{n}\right] \times \\
& {\left[\exp \left(-N T U_{a}^{n}\right)-1\right], \quad i=1, \ldots, N, \quad n=0,1, \ldots}
\end{aligned}
$$

The air temperature behind the tube row can be calculated using $\mathrm{Eq}$. (16)

$$
\begin{aligned}
& \left(T_{a, i}^{\prime \prime}\right)^{n+1}=\left(\bar{T}_{t, i}\right)^{n+1}-\left[\left(\bar{T}_{t, i}\right)^{n+1}-\left(T_{a, i}^{\prime}\right)^{n+1}\right] \\
& \times \exp \left(-N T U_{a}^{n+1}\right), \quad i=1, \ldots, N, \quad n=0,1, \ldots
\end{aligned}
$$

The initial conditions (8-10) and the boundary conditions (11- 12) assume the form:

- initial conditions

$T_{w, i}^{0}=\left.T_{w}\left(x_{i}^{+}\right)\right|_{t=0} \quad n=0, \quad i=1, \ldots, N+1$

$T_{t, i}^{0}=\left.T_{t}\left(x_{i}^{+}\right)\right|_{t=0}, \quad n=0, \quad i=1, \ldots, N$

$T_{a, i}^{0}=\left.T_{a}\left(x_{i}^{+}, y^{+}\right)\right|_{t=0}, \quad n=0, \quad i=1, \ldots, N$

- boundary conditions

$$
\begin{aligned}
& T_{w, 0}^{n}=T_{w}^{\prime}\left(t_{n}\right) i=0, \quad n=0,1, \ldots \\
& T_{a}^{n}\left(x_{i}^{+}, y^{+}=0\right)=T_{a}^{\prime}\left(x_{i}^{+}, t_{n}\right) \quad i=1, \ldots, N, n=0,1, \ldots
\end{aligned}
$$

To assure the calculation stability by the explicit finite difference method, the Courant condition must be fulfilled [19]

$$
\frac{\Delta t}{N_{w}^{n} \tau_{w}^{n} \Delta x^{+}} \leq 1
$$

The water temperature $T_{w, i+1}^{n+1}$, the tube wall temperature $T_{t, i}^{n+1}$ and the air temperature $T_{a, i}^{n+1}$ at the new time step $(n+1)$ were calculated using the expressions (18)-(19) and (21) taking into account the initial conditions (22)-(24) and boundary conditions (25)-(26), and starting at $n=0$. The $\Delta t$ time step resulting from Courant $@$ condition (27) is very small (in the range of several hundredths of a second). In the case of the car radiator analyzed in this paper, the time step $\Delta t$ was 0.02 seconds. The time step of data acquisition (sampling step) is usually much longer, e.g., 1 second. The measured water and air temperatures at the inlet to the heat exchanger were interpolated with natural cubic splines to calculate the temperature of the water $T_{w}^{\prime}(t)$ and the air temperature $T_{a}^{\prime}(t)$ at the inlet to the heat exchanger at a given time step $t_{n}$.

\section{Two-pass model of the PFTHE with two tube rows}

The finite difference model of the car radiator, which is a two-pass, two-row PFTHE, was developed. The mathematical model of the car cooler used in internal combustion engines with a cylinder capacity of $1600 \mathrm{~cm}^{3}$ was based on the single-row heat exchanger model presented in subsection 2. The flow arrangement of the analyzed car cooler is shown in Fig. 3. The heat exchanger is made of oval aluminum tubes with a minimum and maximum external diameter of respectively $d_{\text {min }}=b+\delta_{t}=6.35 \mathrm{~mm}$ and $d_{\max }=b+\delta_{t}=11.82 \mathrm{~mm}$. The wall thickness $\delta_{t}$ of the tube is $0.4 \mathrm{~mm}$ and the fin thickness $\delta_{f}$ is $0.08 \mathrm{~mm}$. The thermal conductivity of aluminum is $207 \mathrm{~W} /(\mathrm{m} \cdot \mathrm{K})$ at $40^{\circ} \mathrm{C}$. The transverse pitch of tube spacing is $p_{1}=18.5 \mathrm{~mm}$, and longitudinal pitch is $p_{2}=17 \mathrm{~mm}$. Plain continuous fins are mounted on tubes with pitch $s=1 \mathrm{~mm}$. The active length of tubes in the car radiator is $L_{t}=520 \mathrm{~mm}$. There are 38 tubes in the first and second pass. In the first pass there are 20 tubes, 10 in each row and the second pass there are 18 tubes, 9 in each row.

\subsection{Air-side heat transfer correlation}

The CFD based heat transfer correlations proposed in the paper [12] for the first and second row of tubes and the double row heat exchanger were used to calculate the Nusselt numbers on the air side. The following N usselt numbers derived in [12] using the results of CFD simulation were adopted for the calculation of the air side heat transfer coefficients in the mathematical model of the car radiator

$$
\begin{aligned}
& \mathrm{Nu}_{a}^{I}=10.0205 \mathrm{Re}_{a}^{-0.0623} \operatorname{Pr}_{a}^{1 / 3}, 150 \leq \mathrm{Re}_{a} \leq 330 \\
& \mathrm{Nu}_{a}^{I I}=0.1648 \mathrm{Re}_{a}^{0.5678} \operatorname{Pr}_{a}^{1 / 3}, 150 \leq \mathrm{Re}_{a} \leq 330 \\
& \mathrm{Nu}_{a}=1.0843 \mathrm{Re}_{a}^{0.2836} \operatorname{Pr}_{a}^{1 / 3}, \quad 150 \leq \mathrm{Re}_{a} \leq 330
\end{aligned}
$$

The classic formula modified by $K$ ays and London [1] was used to calculate the hydraulic diameter $d_{a}$ on the air side. The air side Reynolds number was calculated using the relationship $\mathrm{Re}_{a}=w_{\max } d_{a} / v_{a}$, where the symbol $w_{\max }$ denotes the air velocity in the minimum free flow area. The maximum air velocity $w_{\max }$ which, in the case of an inline tube arrangement, occurs between two adjacent tubes in a given tube row is given by

$$
w_{\max }=\frac{s p_{1}}{\left(s-\delta_{f}\right)\left(p_{1}-d_{o, \min }\right)} \frac{\bar{T}_{a}+273}{T_{a m}^{\prime}+273} w_{0}
$$

where $w_{0}$ is the air velocity in front of the PFTHE. 


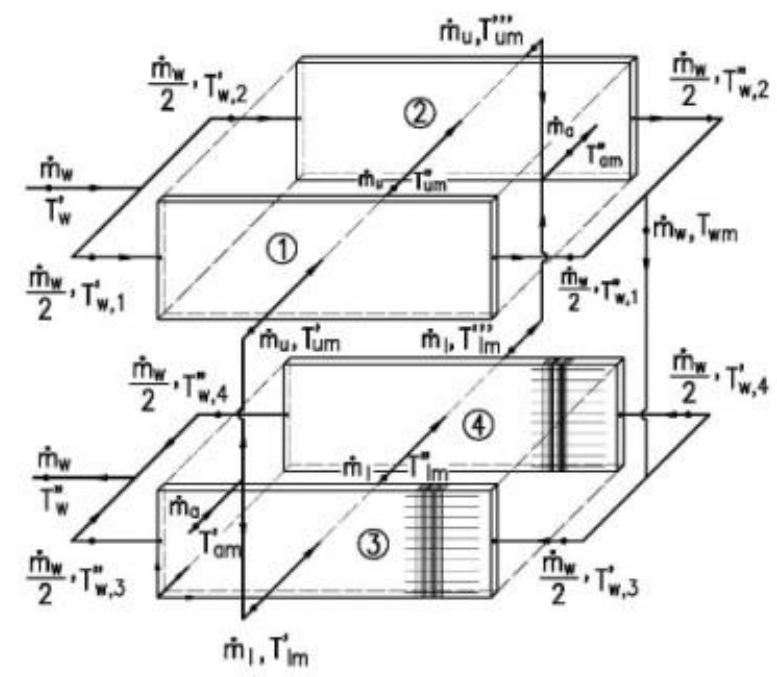

Fig. 3. Flow system of the analyzed two-pass PFTHE (car cooler) with two rows of tubes; 1 - first row of tubes in the first pass, 2 - second row of tubes in the first pass, 3 - first row of tubes in the second pass, 4 second row of tubes in the second pass

A ll physical properties of the air in the relationships (28) - (30) were evaluated at the average air temperature $\bar{T}_{a}=\left(T_{a m}^{\prime}+T_{a m}^{\prime \prime}\right) / 2$, where the symbols $T_{a m}^{\prime}$ and $T_{a m}^{\prime}$ mean the average air temperatures before and after the radiator.

\subsection{Water-side heat transfer correlation}

During transient heat exchanger operation, the flow regime can be laminar, transient, or turbulent.T he mean $\mathrm{N}$ usselt number $\mathrm{Nu}_{m, q}$ for the laminar flow which is hydraulically and thermally developing in a tube with the constant wall heat flux was calculated using the formula recommended by Gnielinski in VDI Heat A tlas [17]

$$
\begin{gathered}
\mathrm{Nu}_{m, q}=\left[\mathrm{Nu}_{m, q, 1}^{3}+0.6^{3}+\left(\mathrm{Nu}_{m, q, 2}-0.6\right)^{3}+\right. \\
\left.\mathrm{Nu}_{m, q, 3}^{3}\right]^{1 / 3}, \quad \mathrm{Re}_{w} \leq 2300
\end{gathered}
$$

The N usselt numbers $\mathrm{Nu}_{m, q, 1}, \mathrm{Nu}_{m, q, 2}$, and $\mathrm{Nu}_{m, q, 3}$ are as follows

$$
\begin{aligned}
& \mathrm{Nu}_{m, q, 1}=\frac{48}{11}=4.364, \operatorname{Re}_{w} \leq 2300 \\
& \mathrm{Nu}_{m, q, 2}=3^{1 / 3} \Gamma(2 / 3)\left(\operatorname{Re}_{w} \operatorname{Pr}_{w} \frac{d_{w}}{L_{t}}\right)^{1 / 3}= \\
& 1.9530\left(\operatorname{Re}_{w} \operatorname{Pr}_{w} \frac{d_{w}}{L_{t}}\right)^{1 / 3}, \operatorname{Re}_{w} \leq 2300 \\
& \mathrm{Nu}_{m, q, 3}=0.924 \operatorname{Pr}_{w}^{1 / 3}\left(\operatorname{Re}_{w} \frac{d_{w}}{L_{t}}\right)^{1 / 2}, \operatorname{Re}_{w} \leq 2300
\end{aligned}
$$

The Nusselt number in the transition and turbulent flow was calculated using the Taler relationship [13]

$$
\begin{gathered}
\mathrm{Nu}_{w}=\left.\mathrm{Nu}_{m, q}\right|_{\mathrm{Re}_{w}=2300}+\frac{\frac{\xi_{w}}{8}\left(\mathrm{Re}_{w}-2300\right) \mathrm{Pr}_{w}^{1.008}}{1.084+12.4 \sqrt{\frac{\xi_{w}}{8}}\left(\mathrm{Pr}_{w}^{2 / 3}-1\right)} \times \\
{\left[1+\left(\frac{d_{w}}{L_{t}}\right)^{2 / 3}\right], 2300 \leq \mathrm{Re}_{w} \leq 10^{6}, 0.1 \leq \operatorname{Pr}_{w} \leq 1000, \frac{d_{w}}{L_{t}} \leq 1}
\end{gathered}
$$

The Darcy-W eisbach friction factor in the turbulent flow range, when $3000 \leq \mathrm{Re}_{w}$ was calculated using the Taler formula [14]

$$
\xi_{w}=\left(1.2776 \log \mathrm{Re}_{w}-0.406\right)^{-2.246} 3000 \leq \mathrm{Re}_{w}
$$

The friction factor for the transition flow was determined using the relationship of Taler proposed in [15-16]

$$
\begin{aligned}
\xi_{w}= & 0.02783+2.2457 \cdot 10^{-5}\left(\mathrm{Re}_{w}-2300\right) \\
& 2300 \leq \mathrm{Re}_{w} \leq 3000
\end{aligned}
$$

The formula (38) represents a linear interpolation of the friction factor between $\mathrm{Re}_{w}=2300$ and $\mathrm{Re}_{w}=3000$. The Reynolds number on water side $\mathrm{Re}_{w}=w_{w} d_{w} / v_{w}$ is based on the hydraulic diameter $d_{w}$. The hydraulic diameter was $d_{w}=7.06 \mathrm{~mm}$. The water physical properties were determined at the average temperature $\bar{T}_{w}=\left(T_{w}^{\prime}+T_{w}^{\prime \prime}\right) / 2$. The relationship (36) was validated experimentally for PFTHE made of oval tubes [18] and for PFTHE made of round tubes [19].

\section{Comparison of simulation results with experimental data}

Transient behavior of the car radiator after a rapid rise in water volume flow rate $\dot{V}_{w}$ and at a sudden drop in air velocity $w_{0}$ at the inlet to the heat exchanger (Fig.3) was studied experimentally. The description of the test facility is presented in detail in the paper [20]. At first, the simulation of the transient response of the PFTHE was conducted for different heat transfer coefficients on each tube row. The heat transfer coefficients on the air side of the first and second row of tubes were calculated using CFD based correlations (28) and (29). Then, the numerical simulation of the car heat radiator was also carried out for a uniform heat transfer coefficient on the first and second row of tubes. In this case, the value of the heat transfer coefficient on both rows of tubes was calculated by applying the CFD correlation (30). The numerical simulation of the PFTHE was conducted with a time step $\Delta t=0.02 \mathrm{~s}$. The temperature of the air $T_{a m}^{\prime}$ and water $T_{w}^{\prime}$ at the inlet to the exchanger was constant. The calculation results shown in Fig. 4 were obtained for a uniform heat transfer coefficient in the entire heat exchanger, which was calculated from the CFD based formula (30). Calculated water and air outlet temperatures of PFTHE was compared with the results of the measurements. The conformity of the calculation and measurement results is very good. The following formulas 
were used to calculate heat flow rates in individual tube rows

$$
\begin{array}{ll}
Q_{1, j H T C}=\left(\dot{m}_{w} / 2\right) \bar{c}_{w}\left(T_{w}^{\prime}-T_{w, 1}^{\prime \prime}\right) & j=1,2 \\
Q_{2, j H T C}=\left(\dot{m}_{w} / 2\right) \bar{c}_{w}\left(T_{w}^{\prime}-T_{w, 2}^{\prime \prime}\right) & j=1,2 \\
Q_{3, j H T C}=\left(\dot{m}_{w} / 2\right) \bar{c}_{w}\left(T_{w m}-T_{w, 3}^{\prime \prime}\right) & j=1,2 \\
Q_{4, j H T C}=\left(\dot{m}_{w} / 2\right) \bar{c}_{w}\left(T_{w m}-T_{w, 4}^{\prime \prime}\right) & j=1,2
\end{array}
$$

The total heat transfer rate from the air to the water was calculated using the expression

$$
\begin{aligned}
& Q_{t, j H T C}=\dot{m}_{w} \bar{c}_{w}\left(T_{w}^{\prime}-T_{w}^{\prime \prime}\right)=Q_{1, j H T C}+ \\
& Q_{2, j H T C}+Q_{3, j H T C}+Q_{4, j H T C} \quad j=1,2
\end{aligned}
$$

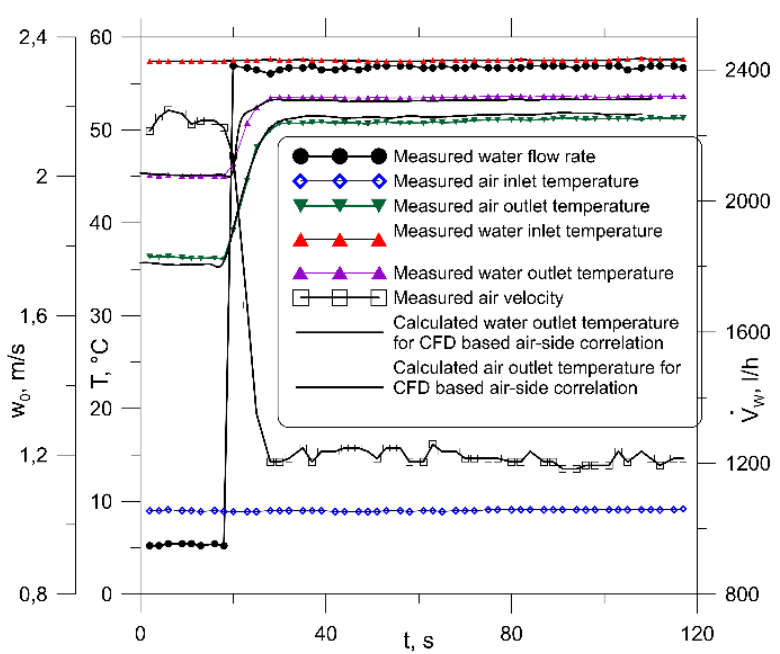

Fig. 4. Transient response of the heat exchanger to a sudden increase in water volume flow rate $\dot{V}_{w}$ and a decrease in air velocity $w_{0}$ at the inlet to the heat exchanger

The symbols $Q_{i, 1 H T C} \quad i=1, \ldots, 4$ denote the heat flow rate exchanged in the individual rows (Fig. 3) on the assumption that the heat transfer coefficient calculated using formula (30) is uniform throughout the heat exchanger. The symbols $Q_{i, 2 \text { HTC }} \quad i=1, \ldots, 4$ denote the heat flow rate transferred in the individual rows, with the heat transfer coefficient in the first row of tubes calculated using the correlation (28) and in the second row using the correlation (29).

If the heat transfer coefficient on the air side is uniform in the whole heat exchanger then in Eqs (39)-(43) $j=1$, and if the heat transfer coefficients on the first and second row of tubes are different then $j=2$. The relative differences between the heat flow rate with different heat transfer coefficients on the first and second row of tubes and the heat flow rate with uniform heat transfer coefficient in the whole heat exchanger were also calculated

$$
e_{i}=\frac{Q_{i, 2 H T C}-Q_{i, 1 H T C}}{Q_{i, 2 H T C}} \cdot 100 \quad i=1, \ldots, 4
$$

The relative $e_{t}$ difference for the whole heat exchanger was calculated with a similar formula

$$
e_{t}=\frac{Q_{t, 2 H T C}-Q_{t, 1 H T C}}{Q_{t, 2 H T C}} \cdot 100
$$

The obtained results show that the first row of tubes in the first and second pass takes up much more heat than the second row if different heat transfer coefficients in the first and second row of tubes are taken into account. Relative $e_{1}$ and $e_{3}$ differences in the heat flow rates exchanged in the first row of the first pass and the first row of the second pass are between 7 and $18 \%$, respectively. Second-row tubes are much less efficient if different heat transfer coefficients are taken into account on both rows of heat exchanger tubes. The tubes in the second row take up between $12.5 \%$ and $50.9 \%$ less heat compared to the heat flow rates exchanged in the second row, assuming a uniform heat transfer coefficient. Relative differences $e_{2}$ and $e_{4}$ are between $(-50.9 \%)$ and $(-12.5 \%)$. The results of numerical simulations show that if the calculation assumes a uniform heat transfer coefficient on the air side for the whole heat exchanger, then an understated value of the heat flow exchanged in the first row, and an overstated value of the heat flow exchanged in the second row is obtained.

The total heat transfer rate $Q_{t}$ in the analyzed heat exchanger is similar for a uniform heat transfer rate on the air side, as well as for different heat transfer rates on the first and second row of tubes. This is clear when taking into account the method of determining the uniform heat transfer coefficient for both tube rows. The heat transfer coefficient is selected from the condition of equal increase of air temperature obtained from the CFD simulation and numerical model of the heat exchanger. Heat transfer coefficients on the first and second row of tubes are determined from the condition of equality of air temperature increase on the first and second row of tubes, respectively, determined by CFD simulation and numerical model. Since the sum of air temperature increments on the first and second row of tubes is equal to the total temperature difference on both rows of tubes, therefore the heat flow rates $Q_{t, 2 \text { НTC }}$ and $Q_{t, 1 \text { HтC }}$ must be similar. Relative differences between $Q_{t, 2 H T C}$ and $Q_{t, 1 H T C}$ are between $(-0.3 \%)$ and $1.7 \%$. These small differences result from the procedure for determining correlations (28)-(30) [12], which assumes that the water temperature in the tubes and the heat transfer coefficient on the internal surface of the tube are constant [12]. Under real conditions, the water temperature changes along the length of the tube. Also, the heat transfer coefficient on the water side is lower in the first pass than in the second pass. It should be stressed, however, that slightly different conditions of operation of tubes in the real heat exchanger than those adopted in the method of determining the correlations (28)-(30) [12] only slightly affect the value of the heat flow rate $Q_{t}$ exchanged in the heat exchanger.

The numerical simulations of the car radiator in steady-state were also carried out for a uniform and nonuniform heat transfer coefficient on the first and second row of tubes. First, calculations were carried out for the analyzed automotive radiator with one CFD correlation given by the formula (30) for the entire radiator. Results 
of these calculations were compared with the results of experimental tests (Fig. 5).Then, the calculations were carried out for different heat transfer coefficients on the first and second row of tubes. The calculations are intended to confirm the usefulness of CFD correlations for the possible replacement of heat transfer correlations determined based on expensive experimental studies. The comparison of the heat flow rate in the PFTHE determined based of the measured water mass flow rate $\dot{V}_{w}$ at the inlet of the PFTHE and water temperature at the inlet and outlet of the PFTHE with the results of heat flow rate calculations using the PFTHE mathematical model is shown in Fig. 5 . The heat flow rates $Q_{w, \exp }$ and $Q_{w, \text { calc }}$ are given by

$$
\begin{aligned}
& Q_{w, \exp }=\dot{V}_{w} \rho_{w}\left(T_{w, \exp }^{\prime}\right) \bar{c}_{w}\left(T_{w, \exp }^{\prime}-T_{w, \exp }^{\prime \prime}\right) \\
& Q_{w, \text { calc }}=\dot{V}_{w} \rho_{w}\left(T_{w, \exp }^{\prime}\right) \bar{c}_{w}\left(T_{w, \exp }^{\prime}-T_{w, \text { calc }}^{\prime \prime}\right)
\end{aligned}
$$

The symbol $\bar{c}_{w}$ denotes the mean specific heat of the water in the range between the outlet and inlet water temperature. The relative difference $e$ between the heat flow rate $Q_{w, \exp }$ determined experimentally, and the heat flow rate $Q_{w, \text { calc }}$ calculated using the mathematical model of the PFTHE was calculated using the formula $e=100\left(Q_{w, \exp }-Q_{w, \text { calc }}\right) / Q_{w, \exp }$.

Fig. 5 also shows a heat flow rate, marked with a solid line, which was calculated for average volumetric flow rate $\dot{\bar{V}}_{w}=326.06 \mathrm{l} / \mathrm{h}$, air inlet temperature $\bar{T}_{a m}^{\prime}=13.62^{\circ} \mathrm{C}$, and water inlet temperature $\bar{T}_{w}^{\prime}=59.61^{\circ} \mathrm{C}$. The average values $\dot{\bar{V}}_{w}, \bar{T}_{a m}^{\prime}$ and $\bar{T}_{w}^{\prime}$ were calculated based on seven data sets. The flow of water in the tubes was laminar. The Reynolds number $\mathrm{Re}_{w, l}$ in the lower pass varied from 1324 to 1445 .

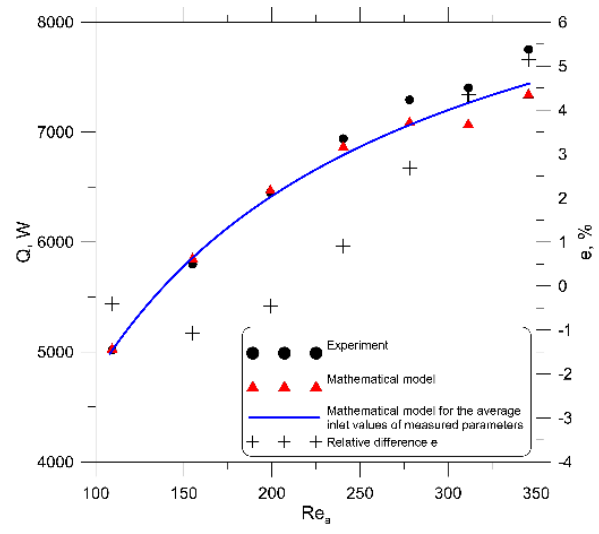

Fig. 5. Heat flow rate transferred from the hot water to the cold air and percentage relative difference $e=100\left(Q_{w, \exp }-Q_{w, \text { calc }}\right) / Q_{w, \exp }$ in $\%$.

Fig. 5 illustrates that the developed numerical model of the heat exchanger using CFD heat transfer correlation to calculate the air-side heat transfer coefficient gives results very close to the experimental data. The largest relative difference $e$ between the heat flow rate determined based on the measurement data and the calculated heat flow rate is $5.14 \%$. Heat flow rates transferred from water to air in the first and second row of tubes in the first and second row of tubes are shown in Figure 6a. The calculations were carried out for a uniform heat transfer coefficient on the first and second row of tubes and different coefficients on each row of tubes. An inspection of the results in Figure 6a indicates that much higher heat flow rate is exchanged in the first row of tubes compared to the second row if the heat transfer coefficients on the first and second tube row are different. This applies to both the first and second heat exchanger passes. The heat flow exchanged in the first row of tubes is about $10 \%$ higher than in the second row for low air velocities in front of the radiator in the range of $0.7 \mathrm{~m} / \mathrm{s}$ when air side Reynolds $\mathrm{Re}_{a}$ number is about 110 .

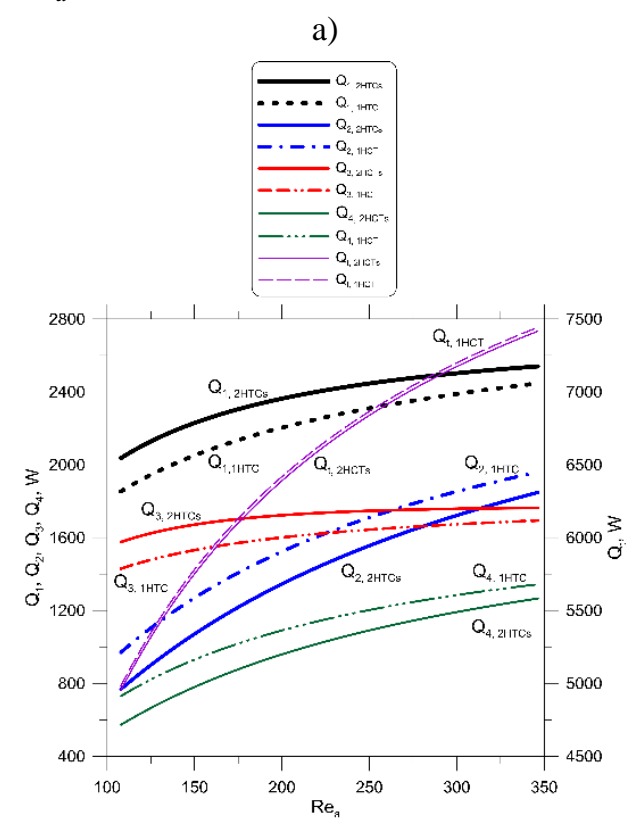

b)

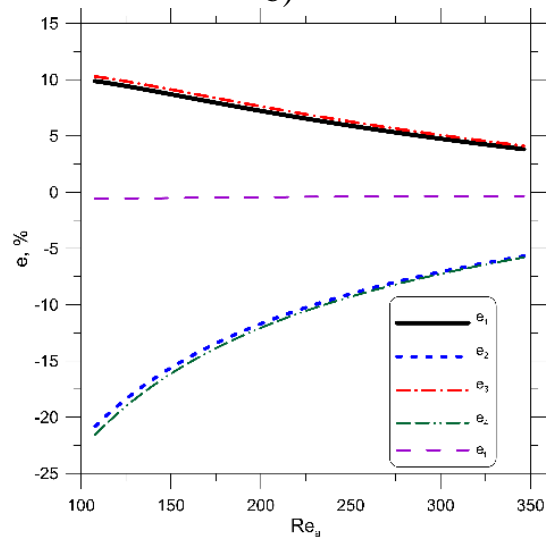

Fig. 6. The heat flow rates exchanged in the first and second row of tubes in the first and second pass for uniform and different heat transfer coefficient on the first and second row of tubes and the relative differences between heat flow rates for different and uniform heat transfer coefficient.

The relative difference between the heat flow absorbed by the air in the first and second row of tubes decreases with increasing air velocity. At an air velocity $w_{0}$ of about $2.25 \mathrm{~m} / \mathrm{s}$, i.e., for $\operatorname{Re}_{a}$ of around 350, the relative 
differences $e_{1}$ and $e_{2}$ decrease to approximately 3.8\% (Fig. 6b). This means that the effect of taking into account different heat transfer coefficients on the individual rows on the transferred heat flow rate decreases as the air velocity increases.

A similar phenomenon of decreasing the relative difference between the exchanged heat flow rate for different and uniform heat transfer coefficients on each tube row is observed for the second tube row. The absolute value of the relative differences $e_{3}$ and $e_{4}$ decreases from approximately $22.5 \%$ for $\mathrm{Re}_{a}=110$ to approximately $6 \%$ for $\operatorname{Re}_{a}=350$.

\section{Conclusions}

The numerical method of PFTHE modeling under transient conditions is presented. It uses heat transfer correlations for heat transfer coefficients on the air side obtained by CFD simulation. The heat exchanger calculations were carried out for a uniform heat transfer coefficient in the whole heat exchanger or different heat transfer coefficients on the first and second row of tubes. In both cases, a very good agreement was achieved between the heat flow rate transferred from hot water to air in the heat exchanger. The results of the calculation of the heat transfer rate in the heat exchanger match the results of the experimental tests very well. The advantage of calculating the heat exchanger with different correlations for the air side Nusselt number on the individual tube rows is that it is possible to determine the heat flow rate from water to air in each tube row.

This information can be used in the design of a heat exchanger because, for example, a more efficient singlerow heat exchanger can be built instead of a double-row heat exchanger by increasing the area of the heat exchange surface in the first row.

\section{References}

1. Kays W. M., London A. L., Compact heat exchangers, $3^{\text {rd }}$ edition, K rieger, M alabar, (1998).

2. M cQuiston F. C., Parker J. D., Spitler J. D., Heating, ventilating, and air conditioning analysis and design, Sixth edition, Wiley, Hoboken NJ USA (2005).

3. Webb R. L., Kim N.H., Principles of enhanced heat transfer, 2nd. ed., Boca Raton, CRC Press, (2005).

4. Taler D., Numerical modelling and experimental testing of heat exchangers, Berlin-H eidelberg: Springer, (2019).

5. Rich D. G., The effect of the number of tube rows on heat transfer performance of smooth plate finand-tube heat exchangers, Paper no. 2345, ASHRAE Transactions, Part 1, V ol. 81, pp. 307-317, (1975).

6. Saboya F. E. M., Sparrow E. M., Experiments on a Three-Row Fin and Tube Heat Exchanger, ASME Journal of Heat Transfer, V ol. 98, pp. 520522, (1976).

7. Wang C.-C., Lee C.-J., C.-T. Chang, S.-P. Lin, Heat transfer and friction correlation for compact louvered fin-and-tube heat exchangers, International Journal of
Heat and Mass Transfer, Vol. 42, pp. 1945-1956, (1999).

8. Taler D, Cebula A. Modeling of air flow and heat transfer in compact heat exchangers, Chemical and Process Engineering, V ol. 25, pp. 2331-2342, (2004).

9. Taler D., Experimental and numerical predictions of the heat transfer correlations in the cross-flow plate fin and tube heat exchangers, Archives of Thermodynamics, Vol. 28 (2007), N o. 2, 3-18.

10. Taler D., Effect of thermal contact resistance on the heat transfer in plate finned tube heat exchangers, Refereed Proceedings of the Conference Heat Exchanger Fouling and Cleaning VII, 1-6 J uly 2007, Tomar, Portugal, E CI, N ew Y ork, pp. 362-371, (2007), http://dc.engconfintl.org/heatexchanger2007/47/.

11. Taler D., Cebula A ., A new method for determination of thermal contact resistance of a fin-to-tube attachment in plate fin-and-tube heat exchangers, Chemical and Process Engineering, Vol. 31, pp. 839-855, (2010).

12. T aler D., Taler J., T rojan M ., Thermal calculations of plate-fin-and-tube heat exchangers with different heat transfer coefficients on each tube row, $14^{\text {th }}$ SDEWES Conference, Dubrovnik, Croatia, October 1-6, 2019 (paper accepted for presentation).

13. Taler $D$., $A$ new heat transfer correlation for transition and turbulent fluid flow in tubes, InternationalJournal of Thermal Science, , V ol. 108, pp. 108-122, (2016).

14. Taler D., Determining velocity and friction factor for turbulent flow in smooth tubes, International Journal of Thermal Science, V ol. 105, pp. 109-122, (2016).

15. Taler D., M athematical modeling and experimental study of heat transfer in a low-duty air-cooled heat exchanger, Energy Conversion and Management ,Vol. 159, pp. 232-243, (2018).

16. Taler D., Taler J., Prediction of heat transfer correlations in a low-loaded plate- fin-and-tube heat exchanger based on flow-thermal tests, Applied Thermal Engineering, Vol. 148, pp. 641-649, (2019).

17. Gnielinski $V_{\text {., }}$ Heat transfer in pipe flow, , in $V D I$ Heat Atlas, Second edition, Springer, Heidelberg, Chapter G1, pp. 693-699, (2010).

18. Taler D., Dynamic response of a cross-flow tube heat exchanger, Chemical and Process Engineering, V ol. 27, pp. 1053-1071, (2006).

19. Taler $D$., Direct and inverse heat transfer problems in dynamics of plate fin and tube heat exchangers, in Heat Transfer - Mathematical Modelling, Numerical Methods and Information Technology, ed. Aziz Belmiloudi, InTech, Rijeka, pp. 77-100 (2011).

20. Taler D., Experimental determination of correlations for average heat transfer coefficients in heat exchangers on both fluid sides, Heat Mass Transfer, Vol. 49, pp. 1125-39, (2013). 